\title{
Penggunaan Anestesi Lokal dan Adjuvan pada Analgesi Epidural di Wilayah Jawa Barat Tahun 2015
}

\author{
Dedi Fitri Yadi, Muhamad Ibnu, Ezra Oktaliansah \\ Departemen Anestesiologi dan Terapi Intensif \\ Fakultas Kedokteran Universitas Padjadjaran/RSUP Dr. Hasan Sadikin Bandung
}

\begin{abstract}
Abstrak
Analgesi epidural yang optimal akan menghasilkan penanganan nyeri yang baik dengan efek samping minimal dan meningkatkan kepuasan pasien. Sampai saat ini belum terdapat data di Indonesia khususnya di wilayah Jawa Barat mengenai penggunaan anestesi lokal dan adjuvan pada analgesi epidural. Tujuan penelitian ini mecari data mengenai penggunaan anestesi lokal dan adjuvan yang digunakan oleh dokter spesialis anestesi di wilayah Jawa Barat pada tahun 2015. Penelitian ini dilakukan pada bulan Agustus hingga September 2016 di Departemen Anestesiologi dan Terapi Intensif RSUP Dr. Hasan Sadikin Bandung. Penelitian ini bersifat deskriptif dengan pengambilan data menggunakan kuesioner dan pendekatan cross sectional. Kuesioner dikirimkan kepada 120 dokter spesialis anestesi di Jawa Barat melalui jasa pos dan 30 kuesioner diberikan langsung kepada dokter spesialis anestesi yang bekerja di RSUP Dr. Hasan Sadikin Bandung. Angka respons yang didapatkan sebesar 47,3\%. Hasil penelitian ini didapatkan dokter spesialis anestesi di Jawa Barat yang masih melakukan analgesi epidural pada tahun 2015 sebesar 73,2\%. Obat anestesi lokal yang paling banyak digunakan untuk analgesi epidural adalah bupivakain sebesar 94,23\%. Konsentrasi terbanyak 0,125\% sebesar 82\%. Adjuvan yang paling banyak digunakan adalah fentanil sebesar 96,9\%. Simpulan penelitian ini sebagian besar dokter spesialis anestesi masih menggunakan epidural sebagai analgesi sehingga bupivakasin dan fentanil menjadi obat terbanyak yang digunakan.
\end{abstract}

Kata kunci: Analgesi epidural, anestesi lokal, adjuvan

\section{Local Anesthetics and Adjuvants Use for Epidural Analgesia in West Java in 2015}

\begin{abstract}
Uncontrolled postoperative pain may cause significant complication on many organs. Adequate postoperative, labor, and chronic pain relief has always been the goal of an anesthesiologist. This goal, however, is not always achieved and continues become a challenge for anesthesiologist. Optimum epidural analgesia should promote effective pain relief with minor adverse event and it can increase patient's satisfaction. Until now, there iss no data on local anesthetics and adjuvant agents use in epidural analgesia by anesthesiologists in Indonesia, especially in West Java. The purpose of this study was to collect data regarding local anesthetics and adjuvant agents used for epidural analgesia by anesthesiologists in Indonesia, especially in West Java, in 2015. This study was conducted from August to September 2016 at the Department of Anesthesiology and Intensive Therapy, Dr. Hasan Sadikin General Hospital Bandung. This was a cross-sectional descriptive study using a questionnaire. This questionnaire was sent to 120 anesthesiologist via mail and was provided directly to 30 nesthesiologists working in Dr. Hasan Sadikin General Hospital Bandung. Response was obtained from $47.3 \%$ of the respondents. This study showed that $73.2 \%$ of anesthesiologists performed epidural analgesia in 2015. The most frequently used local anesthetics inepidural blockade was bupivacaine, amounted to $94.23 \%$ with $0.125 \%$ as the most frequently used concentration, i.e. $82 \%$. For adjuvant, fentanyl was the most frequently used adjuvant, i.e. $96.9 \%$. In conclusion, most anesthesiologists still do epidural anesthesia with bupivacaine and fentanyl as the most used agents.
\end{abstract}

Key words: Epidural analgesia, local anesthetic, adjuvant

Korespondensi: Dedi Fitri Yadi, dr.,SpAn-KAR. M. Kes, Departemen Anestesiologi dan Terapi Intensif Fakultas Kedokteran Universitas Padjadjaran/RSUP Dr. Hasan Sadikin Bandung, Tlpn. 022-2038285, Email dedifyadi@yahoo.com 


\section{Pendahuluan}

Blokade epidural adalah salah satu teknik anestesi regional yang menempatkan obat anestesi lokal di dalam ruang epidural. Banyak keuntungan yang diperoleh dari teknik anestesi regional diantaranya relatif lebih murah, pengaruh sistemik lebih kecil, menghasilkan analgesi adekuat, mampu mencegah respons stres lebih sempurna, dapat menurunkan perdarahan selama pembedahan, serta dapat digunakan untuk penanganan nyeri pascaoperasi. ${ }^{1}$

Nyeri pascaoperasi yang tidak teratasi akan menyebabkan berbagai komplikasi. Penanganan nyeri pascaoperasi yang adekuat menjadi salah satu tujuan bagi dokter spesialis anestesi, dan tujuan ini tidak selalu dapat tercapai. Hal ini merupakan tantangan bagi dokter anestesi. Analgesi tidak hanya penting bagi kenyamanan dan kesejahteraan pasien, namun hal ini penting karena nyeri dapat menimbulkan komplikasi pada jantung maupun pernapasan. Analgesi epidural yang optimal akan menghasilkan penanganan nyeri yang baik dengan efek samping minimal dan meningkatkan kepuasan pasien. Analgesi epidural terbukti dapat menurunkan lama perawatan pada pasien yang dirawat di ICU, meningkatkan fungsi paru-paru, menurunkan angkakomplikasitromboemboli,mempercepat pengembalian fungsi motilitas usus, dan mempercepat lama perawatan di rumah sakit. Analgesi epidural juga dapat memblok stres respons dengan baik, mempercepat mobilisasi pasien, serta menurunkan angka morbiditas dan mortalitas. ${ }^{2}$

Banyak obat yang dapat digunakan untuk menangani nyeri dengan baik melalui epidural. Kombinasi anestesi lokal dosis rendah dengan tambahan opioid saat ini menjadi standar karena kedua obat tersebut memiliki efek yang sinergis. Terdapat beberapa obat selain opioid yang dapat digunakan untuk adjuvan pada epidural antara lain ketamin, klonidin, deksmedemetomidin, midazolam, neostigmin, dan epinefrin. ${ }^{3}$

Jawa Barat merupakan salah satu dari 35 provinsi yang ada di Indonesia yang terdiri atas 9 kota dan 18 kabupaten dengan jumlah dokter anestesi sebanyak 150 orang. Data mengenai penggunaan obat anestesi lokal dan adjuvan untuk analgesi epidural pascaoperasi di negara lain sangat bervariasi sehingga penulis tertarik untuk meneliti hal tersebut.

Berdasar atas latar belakang situasi, kondisi, dan tantangan dapat dirumuskan tema sentral penelitian sebagai berikut:

Analgesi epidural merupakan salah satu teknik yang dapat dilakukan oleh dokter spesialis anestesi dalam penanganan nyeri. Teknik ini dapat digunakan untuk penanganan nyeri pascaoperasi, nyeri pada persalinan, dan kasus lain di luar operasi maupun persalinan. Namun, hingga saat ini di Indonesia khususnya wilayah Jawa Barat belum terdapat data yang tersedia mengenai penggunaan obat anestesi lokal dan adjuvan untuk analgesi epidural. Oleh sebab itu, tujuan penelitian ini adalah mengetahui penggunaan obat anestesi lokal dan adjuvan pada analgesi epidural oleh dokter spesialis anestesi di wilayah Jawa Barat pada tahun 2015.

\section{Subjek dan Metode}

Penelitian ini dilakukan setelah mendapat persetujuan dari Komite Etik Penelitian Kesehatan Fakultas Kedokteran Universitas Padjadjaran/RSUP Dr. Hasan Sadikin Bandung. Penelitian ini dilakukan dengan menyebarkan kuesioner kepada seluruh dokter spesialis anestesi yang menyelesaikan masa studi sebelum tahun 2015 dan masih aktif dalam pelayanan di wilayah perhimpunan Dokter Anestesi dan Terapi Intensif Indonesia (PERDATIN) Jawa Barat pada bulan Agustus hingga September 2016. Sampel yang digunakan merupakan nonprobabilitas dengan teknik purposive sampling.

Penelitian ini merupakan penelitian yang bersifat deskriptif prospektif dengan teknik pengambilan data melalui kuesioner dan pendekatan cross sectional. Data anggota PERDATIN Jawa Barat didapatkan dari sekretariat PERDATIN Jawa Barat yang kemudian dilakukan crosscheck terlebih dahulu dengan cara menghubungi salah satu anggota 
Tabel 1 Penggunaan Analgesi Epidural

\begin{tabular}{lc}
\hline \multicolumn{1}{c}{ Melakukan Analgesi Epidural } & $\mathbf{n = 7 1}$ \\
\hline Masih melakukan & $52(73 \%)$ \\
Tidak melakukan & $19(27 \%)$ \\
\hline
\end{tabular}

PERDATIN pada tiap-tiap wilayah kerja. Data diambil menggunakan amplop yang berisi kuesioner yang disebarkan menggunakan jasa pos. Analisis pengolahan data terhadap kuesioner yang telah di berikan dilakukan mengunakan perangkat lunak Microsoft Excell.

\section{Hasil}

Jumlah dokter spesialis anestesi di wilayah Jawa Barat yang masih melakukan analgesi epidural selama tahun 2015 sebanyak 52 dokter atau sebesar 73\%, dan didapatkan sebanyak 19 dokter spesialis anestesi atau sebesar $27 \%$ tidak melakukan analgesi epidural selama tahun 2015 (Tabel 1).

Dari hasil penelitian didapatkan obat anestesi lokal yang digunakan oleh dokter spesialis anestesi di wilayah Jawa Barat tahun 2015 untuk analgesi epidural paling banyak adalah bupivakain sebesar 83\% (Tabel 2), sedangkan dari 52 dokter spesialis anestesi didapatkan 2 dokter menggunakan lidokain dengan konsentrasi 0,5-1\%. Bupivakain atau ropivakain dengan konsentrasi obat yang paling banyak digunakan adalah 0,125\% sebesar 50\% (Tabel 3).

Obat adjuvan pada analgesi epidural yang

Tabel 3 Konsentrasi Obat Anestesi Lokal untuk Analgesi Epidural

\begin{tabular}{cc}
\hline $\begin{array}{c}\text { Jenis dan Konsentrasi Obat } \\
\text { Anestesi Lokal }\end{array}$ & $\mathbf{n = 5 0}$ \\
\hline $0,0625-0,125 \%$ & $2(4 \%)$ \\
$0,0625-0,25 \%$ & $1(2 \%)$ \\
$0,1 \%$ & $6(12 \%)$ \\
$0,1-0,125 \%$ & $13(26 \%)$ \\
$0,125 \%$ & $25(50 \%)$ \\
$0,125-0,25 \%$ & $1(2 \%)$ \\
$0,25 \%$ & $2(4 \%)$ \\
\hline
\end{tabular}

Tabel 2 Jenis Obat Anestesi Lokal untuk Analgesi Epidural

\begin{tabular}{lc}
\hline Jenis Obat Anestesi Lokal & $\mathbf{n = 5 2}$ \\
\hline Bupivakain & $43(83 \%)$ \\
Lidokain & $2(4 \%)$ \\
Ropivakain & $1(2 \%)$ \\
Bupivakain dan ropivakain & $6(11 \%)$ \\
\hline
\end{tabular}

paling banyak digunakan oleh dokter spesialis anestesi di wilayah Jawa Barat tahun 2015 adalah fentanil sebesar $69 \%$, dokter spesialis anestesi yang menggunakan morfin sebagai adjuvan sebesar $2 \%$. Sebanyak 11 dokter atau sebesar 21\% tidak menggunakan adjuvan untuk analgesi epidural (Tabel 4).

\section{Pembahasan}

Penggunaan epidural untuk persalinan di Amerika meningkat pesat satu dekade belakangan ini, yaitu dari $22 \%$ menjadi $61 \%$ dari tahun 1981 sampai 2001. Di Prancis, $75 \%$ wanita yang menjalani persalinan dipergunakan analgesi epidural, sedangkan di Rumah Sakit Lucile Packard California sekitar $80 \%$ wanita dipergunakan analgesi epidural untuk persalinan. Namun, di Inggris hanya $25 \%$ wanita yang bersalin digunakan analgesi epidural. ${ }^{1}$ Di Jawa Barat didapatkan 73\% dokter spesialis anestesi melakukan analgesi epidural dan 27\% tidak selama tahun 2015.

Lidokain merupakan prototipe dari obat anestesi lokal untuk analgesi epidural dengan konsentrasi 1,5-2\%, namun obat ini dapat menyebabkan fenomena takifilaksis dan meningkatkan risiko toksisitas anestesi lokal. Bupivakain saatini masih menjadi obat anestesi lokal yang banyak digunakan. Levobupivakain merupakan $\mathrm{S}(-)$ enantiomer yang memiliki

\begin{tabular}{lc}
$\begin{array}{l}\text { Tabel } 4 \text { Jenis Adjuvan untuk Analgesi } \\
\text { Epidural }\end{array}$ \\
\hline \multicolumn{1}{c}{ Jenis Adjuvan } & $\mathbf{n = 5 2}$ \\
\hline Fentanil & $36(69 \%)$ \\
Morfin & $1(2 \%)$ \\
Fentanil dan morfin & $4(8 \%)$ \\
Tanpa adjuvan & $11(21 \%)$ \\
\hline
\end{tabular}


toksisitas lebih rendah dibanding dengan bupivakain, begitu juga dengan ropivakain yang memiliki toksisitas terhadap jantung lebih rendah dibanding dengan bupivakain. ${ }^{3}$

Obat anestesi lokal yang paling banyak digunakan untuk analgesi epidural di Jawa Barat adalah bupivakain sebesar 83\%. Meskipun menurut literatur obat ini memiliki toksisitas jantung yang tinggi, namun masih banyak digunakan di Jawa barat. Hal ini serupa di beberapa negara lain. Penggunaan obat anestesi lokal yang paling banyak digunakan di Italia pada tahun 2005, yaitu bupivakain $68,5 \%$ dan ropivakain $23,2 \%{ }^{4}$ Obat anestesi lokal yang paling banyak digunakan di Cina, yaitu bupivakain $70,65 \%$, kemudian ropivakain $28,07 \%$ dan lidokain sebesar $1,28 \% .^{5}$ Beberapa obat anestesi lokal, yaitu ropivakain dan levobupivakain dapat menjadi obat pilihan pada blokade neuroaksial karena memiliki toksisitas yang rendah meskipun diberikan dalam jumlah yang banyak. $^{6}$ Bupivakain merupakan obat anestesi lokal yang sangat kardiotoksik, namun masih menjadi obat anestesi lokal yang paling banyak digunakan oleh dokter anestesi ${ }^{7}$ termasuk di Jawa Barat. Hal ini dikarenakan harganya yang lebih murah dan mudah didapat dibanding dengan ropivakain maupun levobupivakain.

Konsentrasi bupivakain dan ropivakain yang paling banyak digunakan oleh dokter spesialis anestesi di wilayah Jawa Barat tahun 2015 adalah 0,125\% dengan adjuvan yang paling banyak fentanil sebesar $69 \%$. Banyak literatur yang menyatakan bahwa pemberian anestesi lokal konsentrasi kecil dengan opioid untuk epidural banyak digunakan untuk analgesi epidural oleh dokter anestesi. ${ }^{8}$ Regimen obat yang banyak digunakan untuk analgesi epidural adalah bupivakain $0,0625 \%$ dengan adjuvan morfin 25 sampai $50 \mathrm{mcg} / \mathrm{cc}$ atau bupivakain $0,0625 \%$ dengan fentanil 1-10 mcg/cc. ${ }^{3}$ Di Jerman konsentrasi ropivakain yang paling banyak adalah $0,2 \%$ dengan adjuvan sufentanil sebesar $75 \%$. Untuk bupivakain konsentrasi yang paling banyak digunakan $0,25 \%$ dengan adjuvan sufentanil sebesar $60 \%{ }^{9}$

Konsentrasi fentanil yang optimal untuk analgesi epidural belum diketahui hingga saat ini, namun pada satu penelitian didapatkan 3 kombinasi dengan efikasi yang baik antara lain, bupivakain $0,9 \mathrm{mg} / \mathrm{cc}$ ditambah fentanil $3,3 \mathrm{mcg} / \mathrm{cc}$ dengan kecepatan $9 \mathrm{cc} / \mathrm{jam}$, bupivakain 1,3 mg/cc ditambah fentanil $3 \mathrm{mcg} /$ cc dengan kecepatan 7 cc/jam, bupivakain 1,4 $\mathrm{mg} / \mathrm{cc}$ ditambah morfin 2,8 $\mathrm{mcg} / \mathrm{cc}$ dengan kecepatan $9 \mathrm{cc} / \mathrm{jam}^{2}{ }^{2}$

Pada tahun 1999 di Inggris hingga tahun 2008 bupivakain menjadi obat anestesi lokal pilihan utama, sedangkan penggunaan opioid sebagai adjuvan penggunaannya semakin meningkat. ${ }^{10}$ Fentanil merupakan opioid yang sering dipakai di Inggris, memiliki onset yang cepat dan bertahan 1 sampai 2 jam saat diberikan secara bolus. Kombinasi untuk epidural yang popular di Inggris adalah bupivakain $0,1 \%$ atau $0,0625 \%$ dan fentanil $2 \mathrm{mcg} / \mathrm{cc}$. Di Amerika sufentanil banyak digunakan, sufentanil 4-5 kali lebih poten dibanding dengan fentanil untuk epidural. Sufentanil $1 \mathrm{mcg} / \mathrm{cc}$ yang ditambahkan untuk anestesi lokal menghasilkan efek analgesi lebih baik dengan durasi yang lebih lama dibanding dengan fentanil $2 \mathrm{mcg} / \mathrm{cc}^{1}$

Analgesi epidural menggunakan anestesi lokal dan adjuvan opioid memberikan hasil yang lebih baik dibanding dengan pemberian analgesi opioid sistemik maupun analgesi epidural dengan anestesi lokal tanpa adjuvan. ${ }^{2}$ Penggunaan adjuvan paling banyak di Jawa Barat adalah fentanil. Hal ini kemungkinan karena fentanil sangat larut dalam lemak sehingga lebih cepat berikatan pada saraf dan jaringan lemak di rongga epidural, absorpsi kedalam darah cepat sehingga memiliki durasi yang lebih singkat dibanding dengan opioid. Maka dari itu opioid yang lipofilik mempunyai risiko depresi napas lebih rendah. ${ }^{2}$

Meskipun masih terdapat keterbatasan pada penelitian, antara lain ini tidak ditanyakan alasan dokter anestesi dalam memilih suatu jenis maupun konsentrasi obat, namun diharapkan dapat memberikan gambaran mengenai praktik pemberian analgesi pascaoperasi di Jawa Barat pada tahun 2015. Data ini memperlihatkan kebiasaan dokter anestesi di Jawa Barat dalam memberikan 
kombinasi obat untuk analgesi epidural pada tahun 2015.

\section{Simpulan}

Dokter spesialis anestesi di Jawa Barat yang masih banyak melakukan analgesi epidural pada tahun 2015. Obat anestesi lokal yang paling banyak digunakan untuk analgesi epidural adalah bupivakain. Konsentrasi terbanyak $0,125 \%$, adjuvan yang paling banyak digunakan adalah fentanil. Sebagian besar dokter spesialis anestesi masih menggunakan epidural sebagai analgesi sehingga bupivakasin dan fentanil menjadi obat terbanyak yang digunakan.

\section{Daftar Pustaka}

1. Elizabeth M, Kelly L. Epidural analgesia in labour. Contin Educ Anaesth Crit Care Pain. 2004;4(4):114-7.

2. Duarte LT, Fernandes MJ, Fernandes MC, Saravia RA. Continues epidural analgesia: analysis of efficacy, side effect, and risk factor. Rev Bras Anesthesiol. 2004;54:37190.

3. Siriussawakul A, Swanprathep A. Epidural analgesia for periopeative upper abdomen surgery. Dalam: Ogan SF, penyunting. Current view and approach(diunduh tanggal 20 Maret 2016). Tersedia dari: http//www.interchopen.com

4. Allegri M, Niebel T, Bugada D, Coluzzi F, Baciarello M, Berti M, dkk. Regional analgesia in Italy; a survey of current practice. Eur J Pain Suppl. 2010;4:219-25.

5. Huang J, Gao H. Regional anesthesia practice in China: a survey. J Clin Anesth. 2016;34:115-23.

6. Allegri M. Efficacy of drugs in regional anesthesia: a review. Eur J Pain Suppl. 2008;6:118-32.

7. Stourac P, Blaha J, Klozofa R, Noskova P, Seidlova D, Lucie B, dkk. anesthesia for cesarean delivery in the Czech Republic: a national survey. Anesth Analg. 2015;120(6):1303-8.

8. Kampe S, Krenke P, Krombach J dkk. Current practice in postoperative epidural analgesia: a Germany survey. Anesth Analg. 2002;95:1767-9.

9. Wahlen B, Roewer N, Kranke P. Use of local anaesthetics and adjuncts for spinal and epidural anaesthesia and analgesia at German and Austrian University Hospitals: an online survey to assess current standard practice. BMC Anesthesiol. 2010;10(10):4.

10. Jones R, Swales H, Lyons G. A national survey of safe practice with epidural analgesi in obstetric units. J Assoc Great Britain Ireland. 2008;63(5):516-9. 